\title{
Non-malaria fevers in a high malaria endemic area of Ghana
}

\author{
Kwaku Poku Asante ${ }^{1 *}$, Seth Owusu-Agyei ${ }^{1,2}$, Matthew Cairns², Ellen Boamah', Grace Manu', Mieks Twumasi ${ }^{1}$, \\ Richard Gyasi ${ }^{3}$, George Adjei ${ }^{1}$, Kingsley Kayan', Emmanuel Mahama', David Kwame Dosoo', Kwadwo Koram", \\ Brian Greenwood ${ }^{2}$ and Daniel Chandramohan ${ }^{2}$
}

\begin{abstract}
Background: The importance of fevers not due to malaria [non-malaria fevers, NMFs] in children in sub-Saharan Africa is increasingly being recognised. We have investigated the influence of exposure-related factors and placental malaria on the risk of non-malaria fevers among children in Kintampo, an area of Ghana with high malaria transmission.

Methods: Between 2008 and 2011, a cohort of 1855 newborns was enrolled and followed for at least 12 months. Episodes of illness were detected by passive case detection. The primary analysis covered the period from birth up to 12 months of age, with an exploratory analysis of a sub-group of children followed for up to 24 months.

Results: The incidence of all episodes of NMF in the first year of life (first and subsequent) was 1.60 per child-year (95\% $\mathrm{Cl} 1.54,1.66)$. The incidence of NMF was higher among infants with low birth weight [adjusted hazard ratio (aHR) 1.22 (95\% Cl 1.04-1.42) $p=0.012$ ], infants from households of poor socio-economic status [aHR 1.22 (95\% Cl 1.02-1.46) $p=0$. 027] and infants living furthest from a health facility [aHR $1.20(95 \% \mathrm{Cl} 1.01-1.43) p=0.037$ ]. The incidence of all episodes of NMF was similar among infants born to mothers with or without placental malaria [aHR $0.97(0.87,1.08 ; p=0.584)$ ].
\end{abstract}

Conclusion: The incidence of NMF in infancy is high in the study area. The incidence of NMF is associated with low birth weight and poor socioeconomic status but not with placental malaria.

Keywords: Malaria, Non malaria fevers, Fever epidemiology, Cohort study, Ghana

\section{Background}

The burden of malaria in sub-Saharan Africa is still high [1] although there are areas where it has fallen substantially in the past few years as a result of scaling up of coverage with insecticide treated nets (ITN), selective use of indoor residual spraying (IRS) and introduction of efficacious artemisinin-based combination therapy (ACT) [2-6]. The relatively recent introduction of rapid diagnostic tests for malaria has shown that a high proportion of fevers in children are due to other diseases, even in settings with high malaria transmission [7]. As a consequence of the reduction in malaria burden, and the wider use of diagnostics, the importance of fevers not due to malaria (non-malaria fevers, (NMFs)) in malaria endemic areas is gaining increasing recognition [8]. The causal agents of non-malaria fevers are

\footnotetext{
* Correspondence: kwakupoku.asante@kintampo-hrc.org

${ }^{1}$ Kintampo Health Research Centre, Ghana Health Service, P. O. Box, 200,

Kintampo, Brong Ahafo Region, Ghana

Full list of author information is available at the end of the article
}

diverse, vary from area to area and include protozoa, bacteria and viruses [9-11].

Some environmental and social factors are known to be associated with NMF. In a study undertaken in Nigeria, the risk of NMF was increased among the poor and among rural populations [12]. Poverty, high population density, poor water supply and climatic changes are associated with specific infections [13-16]. Another factor identified as a risk factor for NMFs in Benin, West Africa was exposure to malaria antigens in utero, although the mechanism through which this could have been brought about is currently unclear $[17,18]$.

To investigate the influence of social and environmental factors, placental malaria and gravidity on the risk of NMFs among young children, we have analysed data from the Kintampo Birth Cohort Study which was conducted between 2008 and 2011 in an area of Ghana with high malaria transmission [19]. This study provides further understanding of the epidemiology of NMF in a 
high malaria transmission area and provides basis of planning health interventions that target NMF.

\section{Methods \\ Study area}

A prospective birth cohort study to explore the relationship between placental malaria and malaria in infancy was conducted between 2008 and 2011 in the Brong-Ahafo region of Ghana; this study is described in detail elsewhere [19]. Malaria transmission in the study area is high (entomological inoculation rate-269 infective bites/person/ year) and perennial, but transmission peaks between April and October [20]. The health system in the study area is basic and includes public and private health facilities. Infant mortality rate is relatively high, estimated at 52 deaths per 1,000 live births in 2010 [21] and about 40 per 1000 live births in 2013 (Kintampo Health Research Centre, 2015 Report). Laboratory investigations for non-malarial infections are limited to bacterial cultures, which are available in only one health facility.

\section{Study procedures}

The study procedures have been reported in detail elsewhere [19]. In summary, forty-two communities where good follow-up could be obtained were selected from within the Kintampo Health and Demographic Surveillance System (KHDSS). All pregnant women resident in the selected communities were identified using vital registers collated by community key informants or by staff of the KHDSS [21] who made home visits. At enrolment, demographic, socio-economic and obstetric characteristics of study women were recorded by trained fieldworkers using a standard questionnaire. Study women were followed throughout pregnancy until delivery and, whenever possible, a placental sample was obtained. The malaria status of the placenta was defined as showing either 1) an acute infection (parasites present with minimal pigment), 2) a chronic infection (parasites and substantial pigment present) 3) a past malaria infection (substantial pigment only) or 4) no evidence of malaria infection [22, 23].

\section{Enrolment and follow-up of study infants}

Newborns of mothers who had been enrolled in the study prior to delivery were included in the infant cohort study. All infants recruited to the study (with the exception of those who died, migrated or were lost to follow-up) were followed for a minimum of 12 months. However, because recruitment to the study was gradual and children remained in follow-up until the end of the study in May 2011, some children were followed up to 24 months of age.

Episodes of illness were detected passively at study clinics. To maximise capture of fevers, families were provided with health insurance for the duration of the study and encouraged to attend clinics whenever an infant was unwell. Furthermore, community-based fieldworkers facilitated transportation of sick infants to see a study clinician for clinical evaluation. On evaluation by a study clinician, a history of fever within the $48 \mathrm{~h}$ prior to the clinic visit was recorded and an axillary temperature was measured with a digital thermometer.

Infants' illnesses were investigated and managed according to the Ghana National Treatment Guidelines. Rapid diagnostic tests were used to diagnose malaria prior to treatment at the clinic. Thin and thick peripheral blood smears were also made and read subsequently, following the methods described by Swysen et al. [24]. Blood culture, serological or molecular assays for other infectious agents were not done routinely. Non-malaria fevers, the focus of this study, were defined as 1) the presence of fever (a history of fever in the last $48 \mathrm{~h}$ prior the clinic visit OR a measured axillary temperature $\geq 37.5^{\circ} \mathrm{C}$ ) and 2) no malaria parasitaemia detected by microscopy. The cause of death among the study cohort was assessed using verbal post mortem.

\section{Statistical analysis}

Cleaned data were analyzed using STATA 13 (StataCorp, College Station, TX.). Principal component analysis of women's durable assets was used to derive quintiles of socio-economic status (SES), as described previously [19, 25-27]. Cox regression models were used to determine hazard ratios for multiple episodes of NMF, using a robust standard error to account for within-child correlation. The Efron method was used for tied failure times. Potential risk factors including household characteristics: place of residence (urban, rural), household size $(<5,5-9, \geq 10$ residents), socioeconomic status, roof construction (thatched or other); maternal characteristics: number of courses of intermittent preventive therapy in pregnancy (IPTp) received and infant characteristics: sex, birth weight (low, $<2.5 \mathrm{~kg}$; normal), the season of birth (wet, AprilNovember; dry, December-March), and ITN use. ITN use was assessed as tertiles (high, medium or low) based on scores of ITN use in the previous night of scheduled home visits made to access the presence of participants in the study area during follow up.

The primary analysis covered the period from birth up to the age of 12 months. A previous study of nonmalaria fevers in Benin [18] investigated non-malaria fevers by subtype in children less than 18 months of age. Since respiratory and gastrointestinal diseases are common among young children, the analysis was repeated to determine the incidence of NMFs accompanied by gastrointestinal and respiratory symptoms., Since, depending on the date of enrolment, some children were followed for longer than 12 months, we also conducted exploratory analyses of incidence patterns in the period 
0-18 months and 6-18 months of age as in the Benin study.

\section{Ethical approvals}

The study was approved by the ethics committees of the Kintampo Health Research Centre (KHRC), Ghana Health Service, London School of Hygiene \& Tropical Medicine and Noguchi Memorial Institute for Medical Research. Written informed consent was sought from all study women.

\section{Results}

\section{Characteristics of study children}

A cohort of 1855 newborns was recruited and followed; $79.5 \%$ (1475) completed the scheduled 1 year of follow up. Additionally, $39.5 \%$ (737) and $17.4 \%$ (322) were followed for 18 and 24 months respectively (Fig. 1). Six hundred and ninety-five infants $(37.5 \%)$ were born to mothers with placental malaria (PM) (PM + ve children), $355(19 \%)$ to primigravidae (PG) and 1050 (57\%) to mothers who had taken all three scheduled doses of IPTp (Table 1). The majority of infants (1465, $78.9 \%$ ) lived in rural areas. The prevalence of LBW was 40/508
(7.87 \%) in the dry season and 130/1308 (9.9\%) in the wet season $(p=0.175)$. Socio-demographic characteristics such are place of residence, household size, or socioeconomic status were not statistically different among children who died and children who survived (Table 2). Perinatal deaths were the main cause of death among children with a known cause of deaths (Table 3).

\section{Incidence of NMFs}

A total of 2838 episodes of NMF were recorded during the first 12 months of life, 1302 (45.9\%) of which were associated with respiratory symptoms, 911 (32.1\%) with gastro-intestinal symptoms, and $625(22.0 \%)$ with other symptoms. During the same period of follow-up, 1242 febrile malaria episodes were recorded. Sixty-five percent $(1205 / 1855)$ of the study children experienced at least one episode of NMF. The incidence of all (first and subsequent) episodes of NMF in infancy was 1.60 per child-year $(95 \%$ CI 1.54, 1.66). The incidence of NMF was low in early infancy, and rose quickly to around two episodes per child-year between 6 and 8 months of age, after which the incidence reached a plateau (Fig. 2).

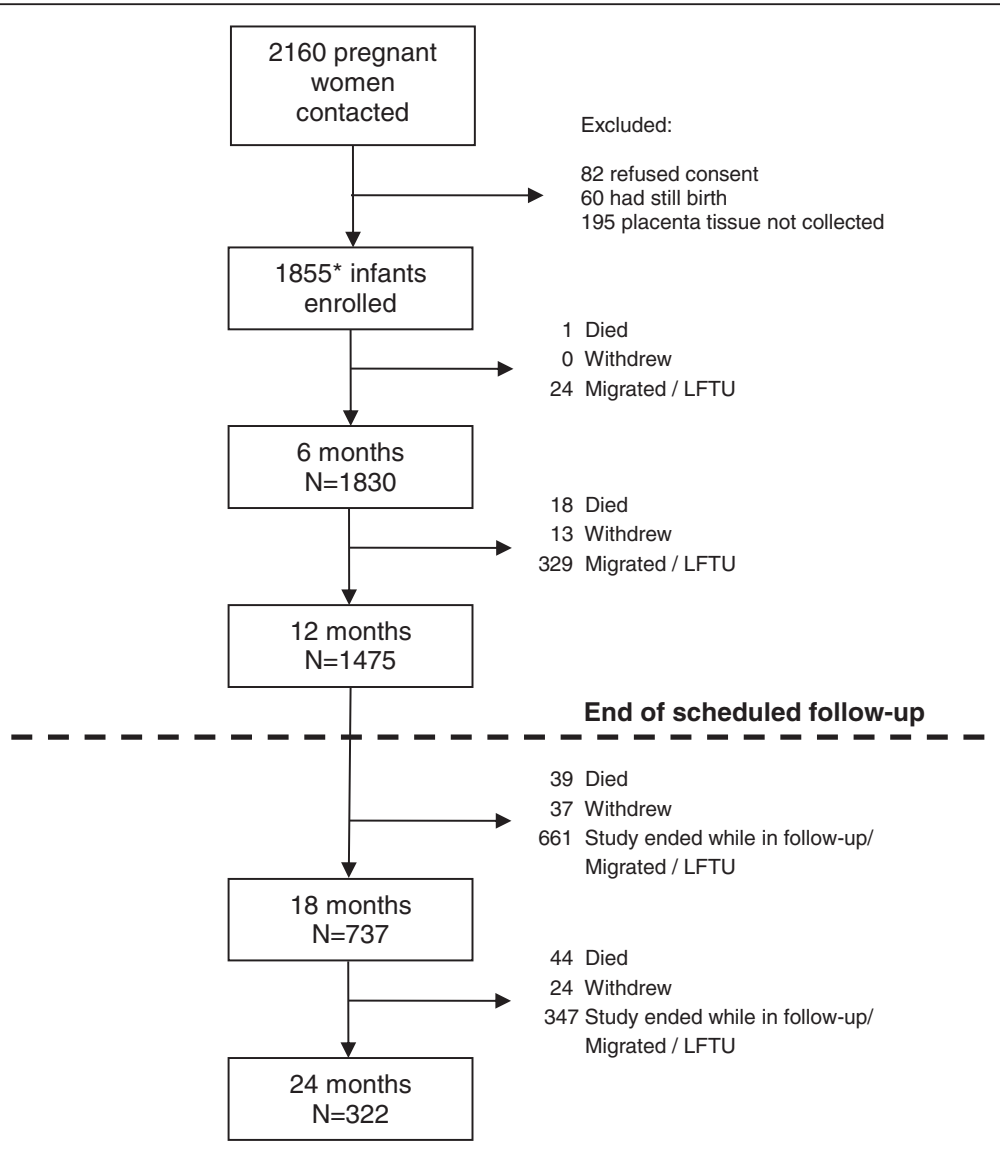

Fig. 1 Study flow diagram of infants born into the Kintampo Birth Cohort Study. ${ }^{*}$ The cohort included 72 children from twin pregnancies 
Table 1 Characteristics of study cohort

\begin{tabular}{llr}
\hline & Attribute & $n(\%)$ \\
\hline Household characteristics & Urban & $390(21.0)$ \\
Place of residence & Rural & $1465(78.9)$ \\
Household size & $<5$ & $937(50.7)$ \\
& $5-9$ & $740(40.1)$ \\
Socio-economic status & $10+$ & $170(9.2)$ \\
& Least poor & $408(22.0)$ \\
& Less poor & $380(20.5)$ \\
& Poor & $322(17.4)$ \\
Thatched roof & More poor & $387(20.9)$ \\
& Very poor & $358(19.3)$ \\
Animals in household & No & $1312(70.7)$ \\
& Yes & $543(29.3)$ \\
Distance from health centre & No & $532(28.7)$ \\
& Yes & $1323(71.3)$ \\
& $1-4.9 \mathrm{~km}$ & $776(41.8)$ \\
& $5-7.9 \mathrm{~km}$ & $620(33.4)$ \\
& 288 km & $171(9.2)$ \\
& &
\end{tabular}

Maternal characteristics

\begin{tabular}{llc} 
Gravidity & Primigravid & $355(19.1)$ \\
Number of IPTp & Multigravid & $1500(80.9)$ \\
Courses & 0 & $97(5.2)$ \\
& 1 & $240(12.9)$ \\
Placental malaria & 3 & $468(25.2)$ \\
& Infected & $1050(56.6)$ \\
Infant characteristics & Non-infected & $695(37.5)$ \\
Birth weight & & $1160(62.5)$ \\
& Normal & \\
Sex & Low birth Weight & $1646(90.6)$ \\
& Male & $945(50.9)$ \\
Season of birth & Female & $910(49.1)$ \\
& Dec-Mar & $521(28.1)$ \\
Bednet use & Apr-Nov & $1334(71.9)$ \\
& High & $587(33.3)$ \\
& Medium & $589(33.4)$ \\
& Low & $588(33.3)$ \\
\hline
\end{tabular}

\section{Risk factors for NMFs}

The incidence of NMF between 0 and 12 months of age was higher in poor children, with incidence elevated in all SES categories relative to the most wealthy group (Table 4). The incidence of NMF was higher among children born during the rainy season (between April and
Table 2 Characteristics of children who died in the study cohort

\begin{tabular}{|c|c|c|c|c|}
\hline \multirow[b]{2}{*}{ Household characteristics } & \multirow[t]{2}{*}{ Attribute } & \multicolumn{2}{|l|}{ Died } & \multirow[t]{2}{*}{$P$-value } \\
\hline & & Yes & No & \\
\hline \multirow[t]{2}{*}{ Place of residence } & Urban & $23(22.5)$ & $367(20.9)$ & \multirow[t]{2}{*}{0.70} \\
\hline & Rural & 79 (77.5) & $1386(79.1)$ & \\
\hline \multirow[t]{3}{*}{ Household size } & $<5$ & $54(52.9)$ & $883(50.6)$ & \multirow[t]{3}{*}{0.29} \\
\hline & $5-9$ & $35(34.3)$ & $705(40.4)$ & \\
\hline & $10+$ & $13(12.8)$ & $157(9.0)$ & \\
\hline \multirow[t]{5}{*}{ Socio-economic status } & Least poor & $20(19.6)$ & $388(22.1)$ & \multirow[t]{5}{*}{0.82} \\
\hline & Less poor & $23(22.5)$ & $357(20.4)$ & \\
\hline & Poor & $15(14.7)$ & $307(17.5)$ & \\
\hline & More poor & $21(20.6)$ & $366(20.9)$ & \\
\hline & Very poor & $23(22.6)$ & $335(19.1)$ & \\
\hline \multirow[t]{2}{*}{ Thatched roof } & No & $60(58.8)$ & $1252(71.4)$ & \multirow[t]{2}{*}{0.01} \\
\hline & Yes & $42(41.2)$ & $501(28.6)$ & \\
\hline \multirow[t]{2}{*}{ Animals in household } & No & $32(31.4)$ & $500(28.5)$ & \multirow[t]{2}{*}{0.54} \\
\hline & Yes & $70(68.6)$ & $1253(71.5)$ & \\
\hline \multirow[t]{4}{*}{ Distance from health centre } & $<1 \mathrm{~km}$ & $35(34.3)$ & $741(42.3)$ & \multirow[t]{4}{*}{0.26} \\
\hline & $1-4.9 \mathrm{~km}$ & $35(34.3)$ & $585(33.4)$ & \\
\hline & $5-7.9 \mathrm{~km}$ & $22(21.6)$ & $266(15.2)$ & \\
\hline & $\geq 8 \mathrm{~km}$ & $10(9.8)$ & $161(9.2)$ & \\
\hline
\end{tabular}

November) than in those born during the dry season [unadjusted hazard ratio (uHR) 1.42 (95 \% CI 1.26-1.60, $p<0.001$ ); adjusted hazard ratio (aHR) 1.39 (95\% CI $1.23-1.56, p<0.001)$ ], higher among children who had a low birth weight compared with children who had normal birth weight [uHR 1.15 (95 \% CI 0.97-1.35, $p=$ 0.100); aHR 1.22 (95\% CI 1.04-1.42), $p=0.012$ ], higher among those living furthest $(>8 \mathrm{Km})$ from the nearest health facility [uHR 1.30 (95\% CI 1.09-1.54, $p=0.003$ ); aHR 1.20 (95 \% CI 1.01-1.43, $p=0.037)]$ and,

Table 3 Cause of death among the study cohort $(N=102)$

\begin{tabular}{llc}
\hline Cause of Death & Number & Percent \\
\hline Unknown & 53 & 52.0 \\
Perinatal death & 24 & 23.5 \\
Septicaemia & 10 & 9.8 \\
Respiratory infection & 4 & 3.9 \\
Diarrhoea & 3 & 2.9 \\
Meningitis & 2 & 2.0 \\
Anaemia & 1 & 1.0 \\
Congenital Malformation & 1 & 1.0 \\
Malaria & 1 & 1.0 \\
Malnutrition & 1 & 1.0 \\
Parasitic disease & 1 & 1.0 \\
Unknown infection & 1 & 1.0 \\
\hline
\end{tabular}




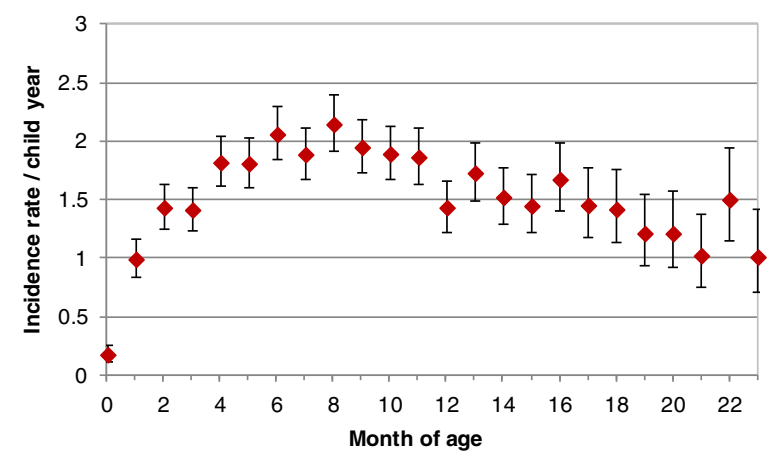

Fig. 2 Incidence of non-malaria fevers during infancy; $95 \%$ confidence interval for the rates are shown

unexpectedly, higher among those whose mothers had used three courses of IPTp [uHR 1.43 (95\% CI 1.12$1.81, p=0.004) ;$ aHR $1.31(1.03,1.68, p=0.030)]$ (Table 4). There was a trend towards an increased risk for each additional course of IPTp taken: aHR 1.12, (1.06, 1.19; $p<0.001)$. The incidence of NMF was lower among girls than boys [uHR 0.90 (95\% CI 0.81-0.99, $p=0.033$ ); aHR 0.87 (95 \% CI 0.79-0.96) $p=0.006$ ] and among children who used their bednet less regularly [uHR 1.13 (95\% CI 1.00-1.28, $p=0.075$ ); aHR 1.15 (95 \% CI 1.021.31) $p=0.024$.

The incidence of NMF between 0 and 12 months of age among children born to mothers without placental malaria was very similar to that observed among children born to mothers who had placental malaria [uHR 1.04 (95 \% CI 0.93-1.15, $p=0.516$ ), aHR 0.97 (95 \% CI $0.87-1.08, p=0.584$ )] (Table 4). The incidence of NMF among children born to primigravidae was very similar to that among children born to multigravidae [uHR 0.94 (95\% CI 0.83-1.07), $p=0.377$, aHR 0.94 (95\% CI 0.821.07) $p=0.367]$ (Table 4). There was no evidence for an interaction between placental malaria and gravidity on the risk of non malaria fevers (Wald test, $p=0.79$ ).

In exploratory analyses making use of the children who were followed for a longer period, there was no difference in the incidence of NMF in children born to mothers with or without PM between 0 and 18 months of age [uHR 1.01 (95\% CI 0.92-1.12), $p=0.816$ ), aHR 0.95 (95 \% CI $0.87-1.05, p=0.349$ )] (Additional file 1: Table S1) or between 6 and 18 months of age [uHR 1.01 (95\% CI 0.911.13), $p=0.808$, aHR 0.96 (95\% CI $0.86-1.07, p=0.418)$ ] (Additional file 2: Table S2). There were also no differences by gravidity over the longer period of follow-up.

\section{Factors associated with NMF and respiratory symptoms}

The factors associated with NMFs accompanied by respiratory symptoms were similar to those associated with all NMFs. Between 0 and 12 months of age, the incidence of respiratory NMFs was higher among those of low birth weight, those born during the rainy season and among those of more poor socioeconomic status (Table 5). There was also a suggestion that girls were at slightly lower risk of respiratory fevers during infancy than boys. There were no differences in the incidence of NMFs associated with respiratory symptoms between children born to mothers with or without placental malaria (Table 5).

\section{Factors associated with NMFs and gastrointestinal symptoms}

The incidence of NMFs associated with gastrointestinal symptoms between 0 and 12 months of age was higher among children from larger households, those from more poor or very poor families, those living far from a health centre and those born during the rainy season (Table 5). As in the main analysis, incidence was higher in children whose mothers had received three doses of IPTp, There was again no difference in the incidence of gastrointestinal NMFs according to placental malaria status (Table 5).

\section{Discussion}

We followed a cohort of 1855 children during infancy, and investigated the relationship between social and environmental factors, placental malaria and gravidity on the incidence of non-malaria fevers (NMFs). Our findings indicate that despite the well-documented high burden of malaria in this setting, non-malaria fevers contribute a larger fraction of the febrile disease burden in the first year of life.

Since cases of NMF were identified passively and therefore dependent on the health seeking behaviour of mother or caregivers of the infants, it is likely that the true incidence of NMF is higher still. It is possible that children living in this high malaria transmission area are predisposed to other febrile illness due to the modulation of the immune system [28-30] that results from repeated malaria infections, as reported previously [31, 32].

The high burden of NMFs in young children is concentrated predominantly among poor families living far from health facilities. Children with low birth weight were found to be at an increased risk of NMFs over the course of the study. Low birth weight infants are known to be at a higher risk of bacterial and viral infections [33], possibly due to their immature immune systems as observed among preterm babies [34]. Male children were at a higher risk of having NMF compared to females. Gender differences in disease epidemiology have been well documented among adults and to a lesser extent among children [35]. The risk of bacterial infections and infant mortality are higher in boys than girls [36-38]. These gender differences may be due to genetic and hormonal differences between boys and girls that may be applicable to our study cohort [39]. However, there may also be differences in care seeking 
Table 4 Hazard ratio for all non malaria fevers with 0-12 months of follow up

\begin{tabular}{|c|c|c|c|c|c|}
\hline \multirow{2}{*}{$\frac{\text { Risk factor }}{\text { Household factors }}$} & & \multirow[t]{2}{*}{ Unadjusted HR (95 \% Cl) } & \multirow[t]{2}{*}{$p$-value } & \multirow[t]{2}{*}{ Adjusted HR (95 \% Cl) } & \multirow[t]{2}{*}{$p$-value } \\
\hline & & & & & \\
\hline \multirow[t]{2}{*}{ Place of residence } & Urban & - & - & - & - \\
\hline & Rural & $1.26(1.11,1.42)$ & $<0.001$ & $0.94(0.78,1.14)$ & 0.519 \\
\hline \multirow[t]{3}{*}{ Household size } & $<5$ & - & - & - & - \\
\hline & $5-9$ & $1.06(0.95,1.18)$ & 0.299 & $1.03(0.92,1.14)$ & 0.632 \\
\hline & $10+$ & $1.17(0.97,1.42)$ & 0.098 & $1.10(0.91,1.32)$ & 0.320 \\
\hline Socio-economic & Least poor & - & - & - & - \\
\hline \multirow[t]{4}{*}{ status } & Less poor & $1.31(1.13,1.54)$ & 0.001 & $1.25(1.07,1.46)$ & 0.005 \\
\hline & Poor & $1.40(1.18,1.65)$ & $<0.001$ & $1.22(1.02,1.46)$ & 0.027 \\
\hline & More poor & $1.59(1.36,1.86)$ & $<0.001$ & $1.46(1.23,1.72)$ & $<0.001$ \\
\hline & Very poor & $1.36(1.15,1.60)$ & $<0.001$ & $1.26(1.05,1.52)$ & 0.012 \\
\hline \multirow[t]{2}{*}{ Thatched roof } & No & - & - & - & - \\
\hline & Yes & $1.21(1.08,1.35)$ & 0.001 & $1.10(0.97,1.24)$ & 0.128 \\
\hline \multirow[t]{2}{*}{ Animals in household } & No & - & - & - & - \\
\hline & Yes & $1.14(1.02,1.29)$ & 0.023 & $1.06(0.95,1.19)$ & 0.307 \\
\hline Distance from health & $<1 \mathrm{~km}$ & - & - & - & - \\
\hline \multirow[t]{3}{*}{ centre } & $1-4.9 \mathrm{~km}$ & $0.83(0.74,0.94)$ & 0.002 & $0.90(0.76,1.06)$ & 0.204 \\
\hline & $5-7.9 \mathrm{~km}$ & $1.19(1.02,1.38)$ & 0.025 & $1.19(1.03,1.37)$ & 0.019 \\
\hline & $\geq 8 \mathrm{~km}$ & $1.30(1.09,1.54)$ & 0.003 & $1.20(1.01,1.43)$ & 0.037 \\
\hline \multicolumn{6}{|l|}{ Maternal factors } \\
\hline \multirow[t]{2}{*}{ Gravidity } & Primigravid & - & - & - & - \\
\hline & Multigravid & $0.94(0.83,1.07)$ & 0.377 & $0.94(0.82,1.07)$ & 0.367 \\
\hline Number of IPTp & 0 & - & - & - & - \\
\hline \multirow[t]{3}{*}{ courses } & 1 & $1.16(0.88,1.53)$ & 0.306 & $1.03(0.77,1.36)$ & 0.862 \\
\hline & 2 & $1.28(1.00,1.65)$ & 0.055 & $1.11(0.86,1.44)$ & 0.432 \\
\hline & 3 & $1.43(1.12,1.81)$ & 0.004 & $1.31(1.03,1.68)$ & 0.030 \\
\hline \multirow[t]{2}{*}{ Placental infection } & Uninfected & - & - & - & - \\
\hline & Infected & $1.04(0.93,1.15)$ & 0.516 & $0.97(0.87,1.08)$ & 0.584 \\
\hline \multicolumn{6}{|l|}{ Infant factors } \\
\hline \multirow[t]{2}{*}{ Birth weight } & Normal & - & - & - & - \\
\hline & Low birth weight & $1.15(0.97,1.35)$ & 0.100 & $1.22(1.04,1.42)$ & 0.012 \\
\hline \multirow[t]{2}{*}{ Sex } & Male & - & - & - & - \\
\hline & Female & $0.90(0.81,0.99)$ & 0.033 & $0.87(0.79,0.96)$ & 0.006 \\
\hline \multirow[t]{2}{*}{ Season of birth } & Dec-Mar & - & - & - & - \\
\hline & Apr-Nov & $1.42(1.26,1.60)$ & $<0.001$ & $1.39(1.23,1.56)$ & $<0.001$ \\
\hline \multirow[t]{3}{*}{ Bednet use } & High & - & - & - & - \\
\hline & Medium & $1.14(1.01,1.28)$ & 0.032 & $1.16(1.03,1.30)$ & 0.015 \\
\hline & Low & $1.13(1.00,1.28)$ & 0.053 & $1.15(1.02,1.31)$ & 0.024 \\
\hline
\end{tabular}

behaviour for illnesses in boys or girls. The incidence of NMF was higher among children born in the long wet season (April-November) compared to children born in the dry season. Birth in the wet season is associated with infections such as respiratory syncytial virus infections [40]. Although we attempted to control for this in a multivariable model, it is also possible that the higher incidence of NMF among infants born during the rainy season may be related to the higher risk of LBW among those born in the wet season.

The finding that NMFs were more frequent in children born to women who had received several courses of 
Table 5 Adjusted hazard ratio (aHR) for all episodes of fever associated with respiratory or gastrointestinal (GI) symptoms between 0 and 12 months of age

\begin{tabular}{|c|c|c|c|c|c|}
\hline \multirow{2}{*}{\multicolumn{2}{|c|}{$\frac{\text { Risk factor }}{\text { Household factors }}$}} & \multirow[t]{2}{*}{ Respiratory aHR (95\% Cl) } & \multirow[t]{2}{*}{$p$-value } & \multirow[t]{2}{*}{$\mathrm{Gl}$ aHR $(95 \% \mathrm{Cl})$} & \multirow[t]{2}{*}{$p$-value } \\
\hline & & & & & \\
\hline \multirow[t]{2}{*}{ Place of residence } & Urban & - & - & - & - \\
\hline & Rural & $0.91(0.70,1.17)$ & 0.442 & $1.02(0.74,1.41)$ & 0.884 \\
\hline \multirow[t]{3}{*}{ Household size } & $<5$ & - & - & - & - \\
\hline & $5-9$ & $1.02(0.89,1.17)$ & 0.729 & $0.89(0.76,1.06)$ & 0.186 \\
\hline & $10+$ & $1.08(0.85,1.37)$ & 0.541 & $1.36(1.05,1.77)$ & 0.021 \\
\hline Socio-economic & Least poor & - & - & - & - \\
\hline \multirow[t]{4}{*}{ status } & Less poor & $1.23(1.00,1.51)$ & 0.050 & $1.38(1.06,1.80)$ & 0.015 \\
\hline & Poor & $1.30(1.03,1.65)$ & 0.027 & $1.28(0.97,1.69)$ & 0.083 \\
\hline & More poor & $1.34(1.08,1.66)$ & 0.008 & $1.47(1.12,1.94)$ & 0.006 \\
\hline & Very poor & $1.15(0.91,1.46)$ & 0.248 & $1.46(1.10,1.95)$ & 0.009 \\
\hline \multirow[t]{2}{*}{ Thatched roof } & No & - & - & - & - \\
\hline & Yes & $1.05(0.89,1.23)$ & 0.575 & $1.15(0.96,1.38)$ & 0.121 \\
\hline \multirow[t]{2}{*}{ Animals in household } & No & - & - & - & - \\
\hline & Yes & $0.99(0.86,1.14)$ & 0.908 & $1.13(0.94,1.35)$ & 0.191 \\
\hline Distance from health & $<1 \mathrm{~km}$ & - & - & - & - \\
\hline \multirow[t]{3}{*}{ centre } & $1-4.9 \mathrm{~km}$ & $0.92(0.74,1.15)$ & 0.464 & $0.90(0.68,1.18)$ & 0.430 \\
\hline & $5-7.9 \mathrm{~km}$ & $1.25(1.04,1.50)$ & 0.017 & $1.30(1.05,1.61)$ & 0.015 \\
\hline & $\geq 8 \mathrm{~km}$ & $1.06(0.82,1.36)$ & 0.649 & $1.51(1.17,1.94)$ & 0.001 \\
\hline \multicolumn{6}{|l|}{ Maternal factors } \\
\hline \multirow[t]{2}{*}{ Gravidity } & Primigravid & - & - & - & - \\
\hline & Multigravid & $1.05(0.88,1.24)$ & 0.592 & $0.83(0.68,1.00)$ & 0.052 \\
\hline Number of IPTp & 0 & - & - & - & - \\
\hline \multirow[t]{3}{*}{ courses } & 1 & $1.14(0.77,1.70)$ & 0.509 & $1.14(0.70,1.85)$ & 0.596 \\
\hline & 2 & $1.12(0.78,1.61)$ & 0.539 & $1.28(0.82,2.01)$ & 0.273 \\
\hline & 3 & $1.31(0.93,1.86)$ & 0.125 & $1.67(1.08,2.59)$ & 0.022 \\
\hline \multirow[t]{2}{*}{ Placental infection } & Uninfected & - & - & - & - \\
\hline & Infected & $0.95(0.82,1.10)$ & 0.529 & $0.97(0.82,1.13)$ & 0.668 \\
\hline \multicolumn{6}{|l|}{ Infant factors } \\
\hline \multirow[t]{2}{*}{ Birth weight } & Normal & - & - & - & - \\
\hline & Low birth weight & $1.27(1.03,1.57)$ & 0.025 & $1.22(0.96,1.55)$ & 0.104 \\
\hline \multirow[t]{2}{*}{ Sex } & Male & - & - & - & - \\
\hline & Female & $0.87(0.76,0.98)$ & 0.027 & $0.98(0.84,1.15)$ & 0.832 \\
\hline \multirow[t]{2}{*}{ Season of birth } & Dec-Mar & - & - & - & - \\
\hline & Apr-Nov & $1.51(1.29,1.76)$ & $<0.001$ & $1.54(1.28,1.85)$ & $<0.001$ \\
\hline \multirow[t]{3}{*}{ Bednet use } & High & - & - & - & - \\
\hline & Medium & $1.15(0.98,1.33)$ & 0.081 & $0.97(0.80,1.17)$ & 0.724 \\
\hline & Low & $1.11(0.95,1.31)$ & 0.195 & $1.04(0.87,1.26)$ & 0.643 \\
\hline
\end{tabular}

IPTp was unexpected. This result was seen in different sub-categories of NMFs, and remained after adjustment for a number of possible confounders including distance from a health centre, place of residence and SES. It also remained in exploratory analyses over a longer period of follow-up. One possibility is that mothers who received IPTp were especially conscientious about seeking care for their children when they were ill, resulting in higher apparent incidence (i.e. the apparent link between higher IPTp use and NMF incidence is a result of confounding 
by care-seeking/access to care). However, if this was the case, it might also be expected that the children of these mothers would have an increased incidence of malaria; this was not found in our previous analysis of children in this cohort [19]. It is difficult to suggest a mechanism by which IPTp could increase the risk of non-malaria fevers, without increasing risk of malaria and consequently this may be a chance finding, or attributable to residual confounding; this should be examined in future studies.

NMFs were no more frequent in children born to women with placental malaria at delivery than in children whose mothers did not have placental malaria either in crude or adjusted analyses. There was also no association between the incidence of NMFs and mothers' gravidity. In a previous study carried out in Benin, placental malaria infection was associated with a higher risk of NMFs among young children [18] and the investigators suggested that exposure to malaria antigens in utero predisposes young infants to NMF [18], as has been suggested previously for malaria [17]. The increased incidence of malaria among infants born to mothers with placental malaria (PM) in relatively low malaria transmission areas [41-45] could be due to exposure of these infants to malaria antigens in utero leading to changes in the immune system which make them more susceptible to malaria [17]. Alternatively, mothers with placental malaria may be at increased risk of malaria due to a combination of social and environmental risks which may be shared with their infants [19]. These social and environment factors could also increase the risk of NMFs in infants born to women who had placental malaria.

The reason for differences between our results and those of the study in Benin is unknown, although we performed analyses to match those undertaken in the Benin study as closely as possible. There were however some methodological differences between the two studies. Firstly, the transmission of malaria in Kintampo was much higher than in Tori Bossito, Benin (entomological inoculation rate (EIR) 269 infectious bites per person per year [20] and 20.5 respectively) [42, 43]. Thus, levels of in utero exposure to malaria may be higher in Kintampo than in Tori Bossito. Secondly, we used placental histology to diagnose placental malaria, a more sensitive test for placental malaria than the use of placental blood smears [46-48], the technique employed in Benin. Therefore we may have detected placental infections in this study that would have been missed in the previous study [18]. This could have biased results in the earlier study if high density infections acquired more recently were more likely to be detected, since this would tend to identify women with higher exposure to malaria (who may therefore be poorer, live in rural areas, etc., and therefore be more susceptible to malaria and NMFs). Finally, more children were followed in the present study than in the study undertaken in Benin. Although it was not possible to observe all study children until 18 months of age, exploratory analyses restricted to those who were followed to 18 months of age and beyond indicated very similar results to our analyses focusing on infancy.

The following potential biases are acknowledged in this study. Firstly, NMF cases were passively detected, therefore the true incidence may have been underestimated depending on the health seeking behaviour of caregivers. To address this, care-givers were provided with free transportation and health insurance, and encouraged to attend study clinics whenever their child was unwell. Secondly, since there is no diagnostic test routinely carried out for the non-malarial causes of fever, it is possible that co-infections of malaria and other causes of fever such as viral infections were misclassified as malaria-only infections. This may also have led to underestimation of the incidence of NMF. Similarly the incidence of NMF may be underestimated if mortality among the study participants were as a result of NMF that were not reported.

Despite these issues that may lead to an underestimate of malaria incidence, and despite the high level of malaria transmission in this area of Ghana, the incidence of NMF is high. This underscores the importance of other causes of fever in many settings where malaria has previously been the major focus. There is an urgent need to determine the most frequent causes of NMFs in different ecological situations to allow the development of therapeutic and preventative strategies based on sound scientific evidence.

\section{Conclusion}

The incidence of NMF is high in the middle belt of Ghana. The incidence of NMF is associated with low birth weight and poor socioeconomic status but not with placental malaria.

\section{Additional files}

Additional file 1: Table S1. Hazard ratio for all episodes of NMF

Additional file 2: Table S2. Hazard ratio for all episodes of NMF between 6 and 18 months of age. (DOC $77 \mathrm{~kb}$ )

\begin{abstract}
Abbreviations
$A C T$, artemisinin-based combination therapy; aHR, adjusted hazard ratio; $\mathrm{Cl}$, confidence interval; EIR, entomological inoculation rate; IPTp, intermittent preventive treatment in pregnancy; IRS, indoor residual spraying; ITN, Insecticide treated nets; KHDSS, Kintampo Health and Demographic Surveillance System; KHRC, Kintampo Health Research Centre; LBW, low birth weight; MG, multigravidae; NMF, non malaria fevers; PG, primigravidae; PM, placental malaria; SES, socio-economic status; $\mathrm{UHR}$, unadjusted hazard ratio
\end{abstract}

\section{Acknowledgements}

We are grateful to the community leaders in the study area, study parents and their infants; staff and management of Kintampo Health Research Centre and the other Ghana Health Service facilities in the study area; the Pathology Department of University of Ghana Medical School especially Mr. Dzomeku, Mr. Martin Adjuik, INDEPTH Network, Ghana and Dr. Jane Bruce of London 
School of Hygiene and Tropical Medicine. We acknowledge the financial support provided by the Division of Microbiology and Infectious Disease, National Institute of Allergy and Infectious Diseases, National Institute of Health, United States of America [Contract no: HHSN266200400016C] for funding the Kintampo Birth Cohort Study; the Gates Malaria Partnership, London School of Hygiene \& Tropical Medicine for supporting placental tissue histology; the Malaria Capacity Development Consortium (MCDC) for supporting laboratory and field personnel cost. MC is supported by a fellowship jointly funded the UK Medical Research Council (MRC) and the UK Department for International Development (DFID) under the MRC/DFID Concordat agreement.

\section{Funding}

The Division of Microbiology and Infectious Disease, National Institute of Allergy and Infectious Diseases, National Institute of Health, United States of America [Contract no: HHSN266200400016C] provided funding for fieldwork and laboratory support for this sudy. The Gates Malaria Partnership, London School of Hygiene \& Tropical Medicine supported placental tissue histology; the Malaria Capacity Development Consortium (MCDC) for supported laboratory and field personnel cost to for additional fieldwork. MC is supported by a fellowship jointly funded the UK Medical Research Council (MRC) and the UK Department for International Development (DFID) under the MRC/DFID Concordat agreement. The funders played no role in the study design, data collection, data analysis nor data interpretation.

\section{Availability of data and materials}

The data for this manuscript is available on request from: enquiries@kintampo-hrc.org.

\section{Authors' contribution}

KPA, SOA, KAK, BG and DC conceived the idea and designed the study. KPA, SOA, EB, GM, DKD, GA, MT collected data. RG, KK and DKD performed biological specimen analysis and its interpretation. MC, KPA, EM performed statistical analysis. KPA wrote the first draft of the manuscript with support from MC. All authors contributed to the data interpretation and manuscript writing. All authors read and approved the final version of the manuscript.

\section{Competing interest}

The authors declare that they have no competing interests.

\section{Consent for publication}

Not applicable.

\section{Ethics approval and consent to participate}

The Kintampo Health Research Centre Institutional Ethics Committee (Federal Wide Assurance Number Office for Human Research Protections Federal Wide Assurance Number 00011103 and IRB registration number 0004854), Ghana Health Service Ethics Review Committee, London School of Hygiene \& Tropical Medicine Ethics Committee and Noguchi Memorial Institute for Medical Research Institutional Review Board approved the study protocol. Written informed consent was sought from all study women who gave consent for their own participation during pregnancy and on behalf of their infants.

\section{Author details \\ ${ }^{1}$ Kintampo Health Research Centre, Ghana Health Service, P. O. Box, 200, Kintampo, Brong Ahafo Region, Ghana. ${ }^{2}$ London School of Hygiene \& Tropical Medicine, Keppel Street, London WC1E 7HT, UK. ${ }^{3}$ Department of Pathology, University of Ghana Medical School, College of Health, Accra, Ghana. ${ }^{4}$ Noguchi Memorial Institute for Medical Research, University of Ghana, AccraP. O. Box LG 581Ghana.}

\section{Received: 21 December 2015 Accepted: 7 June 2016}

\section{Published online: 11 July 2016}

\section{References}

1. World Malaria Report. In. Switzerland: WHO Press; 2014. http://www.who.int/ malaria/publications/world_malaria_report_2014/report/en/.

2. Trape JF, Tall A, Sokhna C, Ly AB, Diagne N, Ndiath O, et al. The rise and fall of malaria in a west African rural community, Dielmo, Senegal, from 1990 to 2012: a 22 year longitudinal study. Lancet Infect Dis. 2014;14(6):476-88.

3. Trape JF, Tall A, Sokhna C, Ly AB, Diagne N, Ndiath O, Mazenot C, Richard V, Badiane A, Dieye-Ba F, et al. Reductions in malaria and anaemia case and death burden at hospitals following scale-up of malaria control in Zanzibar, 1999-2008. Malar J. 2011;10:46.

4. Bhattarai A, Ali AS, Kachur SP, Martensson A, Abbas AK, Khatib R, Al-Mafazy AW, Ramsan M, Rotllant G, Gerstenmaier JF, et al. Impact of artemisininbased combination therapy and insecticide-treated nets on malaria burden in Zanzibar. PLoS Med. 2007;4(11), e309.

5. Okech BA, Mwobobia IK, Kamau A, Muiruri S, Mutiso N, Nyambura J, Mwatele C, Amano T, Mwandawiro CS. Use of integrated malaria management reduces malaria in Kenya. PLoS One. 2008;3(12), e4050.

6. O'Meara WP, Bejon P, Mwangi TW, Okiro EA, Peshu N, Snow RW, Newton CR, Marsh K. Effect of a fall in malaria transmission on morbidity and mortality in Kilifi. Kenya Lancet. 2008;372(9649):1555-62.

7. D'Acremont V, Kilowoko M, Kyungu E, Philipina S, Sangu W, Kahama-Maro J, Lengeler C, Cherpillod P, Kaiser L, Genton B. Beyond malaria-causes of fever in outpatient Tanzanian children. N Engl J Med. 2014;370(9):809-17.

8. WHO Informal Consultation on Fever Management in Peripheral Health Care Settings. A global Review of Evidence and Practice. Geneva, Switzerland: World Health Organization; 2008.

9. Zaidi AK, Thaver D, Ali SA, Khan TA. Pathogens associated with sepsis in newborns and young infants in developing countries. Pediatr Infect Dis J. 2009;28(1 Suppl):S10-8.

10. Rudan I, O'Brien KL, Nair H, Liu L, Theodoratou E, Qazi S, Luksic I, Fischer Walker $\mathrm{CL}$, Black RE, Campbell H. Epidemiology and etiology of childhood pneumonia in 2010: estimates of incidence, severe morbidity, mortality, underlying risk factors and causative pathogens for 192 countries. Journal of global health. 2013;3(1):010401

11. Luksic I, Kearns PK, Scott F, Rudan I, Campbell H, Nair H. Viral etiology of hospitalized acute lower respiratory infections in children under 5 years of age - a systematic review and meta-analysis. Croat Med J. 2013;54(2):122-34.

12. Gayawan E, Arogundade ED, Adebayo SB. A Bayesian multinomial modeling of spatial pattern of co-morbidity of malaria and non-malarial febrile illness among young children in Nigeria. Trans R Soc Trop Med Hyg. 2014;108(7):415-24.

13. Bemis K, Marcus R, Hadler JL. Socioeconomic status and campylobacteriosis, Connecticut, USA, 1999-2009. Emerg Infect Dis. 2014;20(7):1240-2.

14. Eisenberg JN, Desai MA, Levy K, Bates SJ, Liang S, Naumoff K, Scott JC. Environmental determinants of infectious disease: a framework for tracking causal links and guiding public health research. Environ Health Perspect. 2007;115(8):1216-23.

15. Nagi S, Chadeka EA, Sunahara T, Mutungi F, Justin YK, Kaneko S, Ichinose $Y$, Matsumoto S, Njenga SM, Hashizume M, et al. Risk factors and spatial distribution of Schistosoma mansoni infection among primary school children in Mbita District, Western Kenya. PLoS Negl Trop Dis. 2014;8(7), e2991.

16. von Mollendorf C, Cohen C, de Gouveia L, Naidoo N, Meiring S, Quan V, Lindani S, Moore DP, Reubenson G, Moshe M, Eley B, Hallbauer UM, Finlayson H, Madhi SA, Conklin L, Zell ER, Klugman KP, Whitney CG, von Gottberg A. South African IPD Case-Control Study Group. Risk factors for invasive pneumococcal disease among children less than 5 years of age in a high HIV prevalence setting, South Africa, 2010 to 2012. Pediatr Infect Dis J. 2015:34(1):27-34. doi:10.1097/INF.0000000000000484.

17. Malhotra I, Dent A, Mungai P, Wamachi A, Ouma JH, Narum DL, Muchiri E, Tisch DJ, King CL. Can prenatal malaria exposure produce an immune tolerant phenotype? A prospective birth cohort study in Kenya. PLoS Med. 2009:6(7), e1000116.

18. Rachas A, Le Port A, Cottrell G, Guerra J, Choudat I, Bouscaillou J, Massougbodji A, Garcia A. Placental malaria is associated with increased risk of nonmalaria infection during the first 18 months of life in a Beninese population. Clin Infect Dis. 2012;55(5):672-8.

19. Asante KP, Owusu-Agyei S, Cairns M, Dodoo D, Boamah EA, Gyasi R, Adjei G, Gyan B, Agyeman-Budu A, Dodoo T, et al. Placental malaria and the risk of malaria in infants in a high malaria transmission area in ghana: a prospective cohort study. J Infect Dis. 2013;208(9):1504-13.

20. Dery DB, Brown C, Asante KP, Adams M, Dosoo D, Amenga-Etego S, Wilson M, Chandramohan D, Greenwood B, Owusu-Agyei S. Patterns and seasonality of malaria transmission in the forest-savannah transitional zones of Ghana. Malar J. 2010;9:314

21. Owusu-Agyei S, Nettey OE, Zandoh C, Sulemana A, Adda R, Amenga-Etego S, Mbacke C. Demographic patterns and trends in Central Ghana: baseline indicators from the Kintampo Health and Demographic Surveillance System. Glob Health Action. 2012;5:1-11.

22. Bulmer JN, Rasheed FN, Francis N, Morrison L, Greenwood BM. Placental malaria. I. Pathological classification. Histopathology. 1993;22(3):211-8. 
23. Ismail MR, Ordi J, Menendez C, Ventura PJ, Aponte JJ, Kahigwa E, Hirt R, Cardesa A, Alonso PL. Placental pathology in malaria: a histological, immunohistochemical, and quantitative study. Hum Pathol. 2000;31(1):85-93.

24. Swysen C, Vekemans J, Bruls M, Oyakhirome S, Drakeley C, Kremsner P, Greenwood B, Ofori-Anyinam O, Okech B, Villafana T, et al. Development of standardized laboratory methods and quality processes for a phase III study of the RTS, S/AS01 candidate malaria vaccine. Malar J. 2011;10:223.

25. Houweling TA, Kunst AE, Mackenbach JP. Measuring health inequality among children in developing countries: does the choice of the indicator of economic status matter? Int J Equity Health. 2003;2(1):8.

26. Howe LD, Galobardes B, Matijasevich A, Gordon D, Johnston D, Onwujekwe O, Patel R, Webb EA, Lawlor DA, Hargreaves JR. Measuring socio-economic position for epidemiological studies in low- and middle-income countries: a methods of measurement in epidemiology paper. Int J Epidemiol. 2012;41(3):871-86.

27. Vyas S, Kumaranayake L. Constructing socio-economic status indices: how to use principal components analysis. Health Policy Plan. 2006;21(6):459-68.

28. Lokken KL, Mooney JP, Butler BP, Xavier MN, Chau JY, Schaltenberg N, Begum RH, Muller W, Luckhart S, Tsolis RM. Malaria parasite infection compromises control of concurrent systemic non-typhoidal Salmonella infection via IL-10mediated alteration of myeloid cell function. PLoS Pathog. 2014;10(5), e1004049.

29. Hviid L, Theander TG, Abdulhadi NH, Abu-Zeid YA, Bayoumi RA, Jensen JB. Transient depletion of T cells with high LFA-1 expression from peripheral circulation during acute Plasmodium falciparum malaria. Eur J Immunol. 1991;21(5):1249-53.

30. Theander TG, Hviid L, Abu-Zeid YA, Abdulhadi NH, Saeed BO, Jakobsen PH, Reimert CM, Jepsen S, Bayoumi RA, Jensen JB. Reduced cellular immune reactivity in healthy individuals during the malaria transmission season. Immunol Lett. 1990;25(1-3):237-42.

31. Church J, Maitland K. Invasive bacterial co-infection in African children with Plasmodium falciparum malaria: a systematic review. BMC medicine. 2014;12:31.

32. Berkley JA, Bejon P, Mwangi T, Gwer S, Maitland K, Williams TN, Mohammed S, Osier F, Kinyanjui S, Fegan G, et al. HIV infection, malnutrition, and invasive bacterial infection among children with severe malaria. Clin Infect Dis. 2009:49(3):336-43.

33. Jackson S, Mathews KH, Pulanic D, Falconer R, Rudan I, Campbell H, Nair H. Risk factors for severe acute lower respiratory infections in children: a systematic review and meta-analysis. Croat Med J. 2013;54(2):110-21.

34. Melville JM, Moss TJ. The immune consequences of preterm birth. Front Neurosci. 2013;7:79.

35. Baggio G, Corsini A, Floreani A, Giannini S, Zagonel V. Gender medicine: a task for the third millennium. Clin Chem Lab Med : CCLM/FESCC. 2013;51(4):713-27.

36. Seale AC, Blencowe H, Manu AA, Nair H, Bahl R, Qazi SA, Zaidi AK, Berkley JA, Cousens SN, Lawn JE. pSBI Investigator Group. Estimates of possible severe bacterial infection in neonates in sub-Saharan Africa, south Asia, and Latin America for 2012: a systematic review and meta-analysis. Lancet Infect Dis. 2014;14(8):731-41. doi:10.1016/S1473-3099(14)70804-7. Epub 2014 Jun 25.

37. Wang H, Dwyer-Lindgren L, Lofgren KT, Rajaratnam JK, Marcus JR, LevinRector A, Levitz CE, Lopez AD, Murray CJ. Age-specific and sex-specific mortality in 187 countries, 1970-2010: a systematic analysis for the Global Burden of Disease Study 2010. Lancet. 2012;380(9859):2071-94.

38. Nair H, Simoes EA, Rudan I, Gessner BD, Azziz-Baumgartner E, Zhang JS, Feikin DR, Mackenzie GA, Moisi JC, Roca A, et al. Global and regional burden of hospital admissions for severe acute lower respiratory infections in young children in 2010: a systematic analysis. Lancet. 2013;381(9875):1380-90.

39. Del Principe D, Marconi M, Matarrese P, Villani A, Malorni W. Gender disparity in pediatric diseases. Curr Mol Med. 2013;13(4):499-513.

40. Turner C, Turner P, Cararra V, Eh Lwe N, Watthanaworawit W, Day NP, White NJ, Goldblatt D, Nosten F. A high burden of respiratory syncytial virus associated pneumonia in children less than two years of age in a South East Asian refugee population. PLoS One. 2012;7(11), e50100.

41. Le Hesran JY, Cot M, Personne P, Fievet N, Dubois B, Beyeme M, Boudin C, Deloron P. Maternal placental infection with Plasmodium falciparum and malaria morbidity during the first 2 years of life. Am J Epidemiol. 1997;146(10):826-31.

42. Le Port A, Cottrell G, Martin-Prevel Y, Migot-Nabias F, Cot M, Garcia A. First malaria infections in a cohort of infants in Benin: biological, environmental and genetic determinants. Description of the study site, population methods and preliminary results. BMJ Open. 2012;2(2):e000342.

43. Le Port A, Watier L, Cottrell G, Ouedraogo S, Dechavanne C, Pierrat C, Rachas A, Bouscaillou J, Bouraima A, Massougbodji A, et al. Infections in infants during the first 12 months of life: role of placental malaria and environmental factors. PLoS One. 2011;6(11), e27516.
44. Mutabingwa TK, Bolla MC, Li JL, Domingo GJ, Li X, Fried M, Duffy PE. Maternal malaria and gravidity interact to modify infant susceptibility to malaria. PLoS Med. 2005;2(12), e407.

45. Schwarz NG, Adegnika AA, Breitling LP, Gabor J, Agnandji ST, Newman RD, Lell B, Issifou S, Yazdanbakhsh M, Luty AJ, et al. Placental malaria increases malaria risk in the first 30 months of life. Clin Infect Dis. 2008;47(8):1017-25.

46. Bako BG, Audu BM, Geidam AD, Kullima AA, Ashiru GM, Malah MB, Ngadda $H A$, Musa AB. Prevalence, risk factors and effects of placental malaria in the UMTH, Maiduguri, North-eastern, Nigeria: a cross-sectional study. J Obstet Gynaecol. 2009;29(4):307-10.

47. Okoko BJ, Ota MO, Yamuah LK, Idiong D, Mkpanam SN, Avieka A, et al. Influence of placental malaria infection on foetal outcome in the Gambia: twenty years after lan Mcgregor. J Health Popul Nutr. 2002;20(1):4-11.

48. Rogerson SJ, Mkundika P, Kanjala MK. Diagnosis of Plasmodium falciparum malaria at delivery: comparison of blood film preparation methods and of blood films with histology. J Clin Microbiol. 2003;41(4):1370-4.

\section{Submit your next manuscript to BioMed Central and we will help you at every step:}

- We accept pre-submission inquiries

- Our selector tool helps you to find the most relevant journal

- We provide round the clock customer support

- Convenient online submission

- Thorough peer review

- Inclusion in PubMed and all major indexing services

- Maximum visibility for your research

Submit your manuscript at www.biomedcentral.com/submit
CioMed Central 